\title{
Smile Esthetics - Evaluation of Differential Perception among Laypersons, Dental professionals and Orthodontists
}

\author{
${ }^{1}$ Poorya Naik. D.S, ${ }^{2}$ Mala Ram Manohar, ${ }^{3}$ G.Shivaprakash,${ }^{4}$ Nazima Jabeen. \\ ${ }^{1}$ Asistant.Professor, Department of Orthodontics and Dentofacial Orthopedics College of Dental Sciences. \\ Davangere-577004 \\ ${ }^{2}$ Professor, Department of Orthodontics and Dentofacial Orthopedics College of Dental Sciences. Davangere- \\ 577004 \\ 3 Professor and Head Department of Orthodontics and Dentofacial Orthopedics College of Dental Sciences \\ Davangere-577004 \\ ${ }^{4}$ Asistant.Professor,Department of Orthodontics and Dentofacial Orthopedics College of Dental Sciences. \\ Davangere-577004
}

\begin{abstract}
Introduction: Orthodontic treatment is based on occlusal relationships, but with the changing paradigm, facial esthetics and smile have gained importance. Perception of esthetics by peers has become relevant to the patient. The objective of this study was to compare the perception of smile esthetics by three panel groups include Orthodontists, Dental professionals and Lay persons.

Materials and Methods: 45 female subjects were selected (15 treated with extraction, 15 treated with nonextraction and 15 untreated /control group). Frontal and three-quarter view photographs in unforced, natural smiling positions were taken. These close-up smile photos were evaluated by a panel consisting of 10 orthodontists, 10 dental professionals \& 10 lay persons. Each panel members rated the attractiveness of the smile on a 5-point esthetic scale.

Results: The mean esthetic scores for the Extraction, Non-extraction, and Control groups of 3.01, 3.07, and 2.77 respectively showed no significant differences in over all scores given by the three panels.

Interpretation \& Conclusion: Subjects with ideal occlusions and Class I patients treated with or without extractions could not be differentiated by the three panel of judges by evaluating the smile.

Keywords: Perception, Smile Esthetics, Extraction, Non-Extraction, Control.
\end{abstract}

\section{INTRODUCTION}

From ancient societies and cultures to our modern society, a great emphasis has been placed on facial esthetics and physical attractiveness. The concept of esthetics is subjective, so it is very hard to determine objective criteria for defining the concept of beauty.

Ethnic and racial differences play a major role in diversifying esthetic preferences. Several factors such as sex, age, education, socioeconomic status, and geographic location also affect the esthetic preferences of the public. ${ }^{1}$

Facial attractiveness plays a key role in social interaction. It influences mating success, kingship opportunities, personality evaluations, performance, and employment prospects. Facial attractiveness and smile attractiveness appear strongly connected to each other. The fact is that in social interaction, one's attention is mainly directed toward the mouth and eyes of the speaker's face. As the mouth is the center of communication in the face, the smile plays an important role in facial expression and appearance.

Smile, defined as a facial expression characterized by upward curving of the corners of the mouth, is often used to indicate pleasure, amusement, or derision. The smile, which is essential to express friendliness, agreement, and appreciation, and to convey compassion and understanding, should not be ignored in diagnosis and treatment planning. The goal of modern orthodontics is to establish the best possible occlusal relationship between the maxillary and mandibular dentition while maintaining or enhancing facial esthetics ${ }^{2}$.

\section{OBJECTIVES OF THE STUDY}

1. To evaluate the differential perception of smile esthetics among Lay persons, General Dentists and Orthodontist.

2. To compare the smile esthetics in extraction, non -extraction patients with a control group (untreated patients).

\section{REVIEW OF LITERATURE}

Ricketts was the first to claim that the analysis of a physically beautiful face should be approached mathematically, and he advocated the use of golden proportions in that respect. He observed the photographs of 
magazine models to select pairs of distances representing golden proportions in those beautiful faces. On this basis, he performed a small study using 10 beautiful faces and defined several golden proportions in them. ${ }^{3}$

A study was conducted by Mackley ${ }^{4}$ to evaluate the smiles before and after orthodontic treatment. A panel of five orthodontists and six parents was selected to evaluate the photographs. The average score given by the orthodontists was compared with the average score of the parents.

Johnson and Smith ${ }^{5}$ described the smile esthetics after orthodontic treatment with and without extraction of 4 first premolars. A panel of 10 laypersons judged smile esthetics and found no significant differences in the mean esthetic score of extraction and non extraction patients.

Zachrisson ${ }^{6}$ proposed a method to digitally measure the smile characteristics of orthodontic patients. The 'posed smile' was selected for measurement. Since the posed smile is reliably repeatable.

Isiksalet al ${ }^{7}$ evaluated smile esthetics, perception and comparison of treated and untreated smiles. Panels of orthodontists, plastic surgeons, artists, general dentists, dental professionals, and parents used a 5-point scale to rate smiling photographs of 25 extraction, 25 nonextraction, and 25 untreated control subjects. The mean esthetic scores for the extraction, non-extraction, and control groups were similar.

Mir et al ${ }^{8}$ studied perception of smile esthetics in different dental and facial views rated by 91 randomly selected adult lay persons. Anterior visible occlusion, photographed subject and view type influenced the esthetic perception of smile. Also gender and the interaction between gender and level of education had a significant effect on the aesthetic ratings. They concluded that the aesthetic impact of dental view decreased in a full facial smile view.

\section{METHODOLOGY}

Subjects were selected from the Department of Orthodontics and Dentofacial orthopedics, College of Dental Sciences, Davangere. The total sample size of 45 female subjects consisted of 15 patients treated with extraction of all first premolars, 15 non-extraction patients and 15 untreated (control) group chosen from students of College of Dental Sciences, Davangere. The mean ages were $21.07 \pm 2.84$ years in the extraction, $21.87 \pm 1.68$ years in the non-extraction, and $20.87 \pm 1.68$ years in the control group. All treated and control subjects had skeletal class I with normal occlusion, ideal over jet and overbite.

The photographic set-up consisted of a tripod (Harison Mega Mx-2100) that held camera (Nikon, Coolpix P5100) with a built-in flash. The camera was used in its Automatic Focus (AF) mode; this was done to reduce intra-operator error. The distance between the camera and the stool was fixed at 4 feet for all the subjects. Frontal and Three- quarter view unforced, natural smiling photographs (Fig. 1\&2) were taken for each subject, by the same investigator at a constant object to lens distance with the same digital camera Nikon, (Model: Coolpix P5100)

The images were then transferred to computer software (Adobe Photoshop), they were cropped with vertical (nose tip and soft-tissue pogonion) and transverse (perpendicular drawn down from the zygomatic prominence limits (Fig.2\&3). These images were converted into black and white images for power point slides show. ${ }^{7}$ These cropped images were evaluated by a panel group consisting of 10 Orthodontists, 10 General Dentists \& 10 Lay persons. The slides were shown in a random order to all the panel members. Each panel member have rated the attractiveness of the smile on a 5- point esthetic scale with, (1) poor, (2) fair, (3) good, (4) very good \& (5) excellent.

\section{STATisTiCal ANALYSIS}

All the data were analyzed with MINITAB version 13.1 \& SPSS soft wares. Results are presented as mean $\pm \mathrm{SD}$, number and percentages for categorical data. Smile esthetics and difference among the 3 groups were subjected to one-way analysis of variance (ANOVA). Additionally multiple comparisons were performed with the Bonferroni test. For all the tests a p-value of 0.05 or less was considered for statistical significance.

\section{Results}

One-way analysis of variance (ANOVA) was used to compare smile esthetics and differences among the 3 groups. According to the one way ANOVA mean esthetic scores as evaluated by 3 panel groups for extraction treated, non-extraction treated and control group were 3.01, 3.07 and 2.7 respectively did not differ statistically $(p>0.05)$ in mean esthetic score.(Table.I)

Mean scores given by Orthodontists for Extraction, Non-extraction and Control group were 2.96, 2.81 and 2.6 respectively. The difference in esthetic scores between these three groups was not statistically significant ( $p>0.05)$ (Table. I, Graph.1)

Mean scores given by Dental professionals for extraction; Non-extraction and Control group were 3.08, 3.40 and 2.92 respectively (Graph.2). Esthetic scores between these three groups differed significantly $(\mathrm{p}<0.05)$. The difference was between Non-extraction and Control groups. (Table. I, Graph.2) 
Mean scores given by Lay persons for Extraction, Non-Extraction and Control group were 2.96, 3.02 and 2.78 respectively. Differences inesthetic scores between these three groups were not statistically significant ( $\mathrm{p}>0.05)$. (Table.I, Graph.3).

Repeated measures ANOVA were applied to determine difference among the panels and multiple comparisons were made by Bonferroni test. In extraction group, the mean scores given by Orthodontists, Dental professionals and Lay persons were 2.96, 3.08 and 2.96 respectively, there was no significant $(\mathrm{p}>0.05)$ difference in mean esthetic scores given by three panels groups. (TableII, Graph.4)

In Non-extraction group, the mean scores given by Orthodontists, Dental professionals and Lay persons were 2.81, 3.40 and 3.02 respectively. Repeated measures ANOVA showed highly significant values (0.001 HS) among mean score rating by the 3 panel groups. On multiple comparisons there was significant difference among Orthodontist and Dental professionals, and among Dental professionals and Lay persons (Table.II, Graph.5).

In the control group, the mean scores given by Orthodontists, Dental professionals and Laypersons were 2.6, 2.92 and 2.78 respectively. Repeated measures ANOVA and Bonferroni tests showed significant difference $(<0.05)$ in scoring rates between Orthodontists and Dental professionals. (Table. II, Graph.6).

\section{Discussion}

An attractive, well balanced smile can be a valuable personal asset. Dale Carnige said that most important ways to win friends and influence people is to smile. It is important for orthodontists to make every effort to develop harmonious balance that will produce the most attractive smile possible for each person being treated. ${ }^{6}$ Even a well treated orthodontic case in which the plaster cast meet every criterion of the American Board of Orthodontics for successful treatment may not produce an esthetic smile. ${ }^{8}$ Janzen $^{4}$ advised that a wellbalanced smile is the most important treatment objective.

Wylie" emphasized, "The goal of the orthodontic treatment should be the attainment of best possible esthetic results both dentally and facially."Over the years various studies have been done on human faces describing smile esthetics by taking various quantitative and qualitative soft tissue measurements of the face at rest as well as during smile to describe the various parameters influencing subject's smile. Most of the studies have been carried out in which perception and comparison in males and females, but no studies have been undertaken exclusively in female subjects.

Variation in smile esthetics of male and female has been described in the literature. Peck et.al ${ }^{10}$ and Tjan and Miller ${ }^{11}$ found that low smile lines are predominantly male characteristics ( 2.5 to one male to female) and high smile line is predominantly female ( two to one female to male). Vig and Brundo ${ }^{12}$ found sexual dimorphism maxillary anterior teeth display was almost twice as often in women as in men, the men displayed much more of mandibular incisors, and females were found to be twice likely as males to have a gummy smile. Evidence suggests that the esthetic components for men, women and various races are not entirely the same. Frush and Fischer ${ }^{13}$ pointed out that the women tend to present softer appearance than the men and should therefore be given a softer, rounder and delicate dental appearance. Rigsbee ${ }^{14}$ et.al found that women have greater facial animation characteristics than do men. Hence this study focused mainly on smile esthetics of female subjects.

The present study demonstrated the differences and similarities in how Orthodontists, Dental Professionals and Lay persons evaluated the smile esthetics. An insight into mean scores given by the different panels reveals valuable information.

Orthodontists rated Extraction cases best for smile esthetics, followed by Non-extraction and finally Control. However, the difference between the three groups was not statistically significant ( $>0.05)$ (Table.I). Dental professionals gave higher actual esthetic scores than the Orthodontists and Lay persons, rating the Non extraction group best in smile esthetics and the Control group rated as least attractive and the difference was statistically significant $(\mathrm{p}<0.05)$. Laypersons too rated Non-extraction group best followed by Extraction and Controls. However, the difference was not statistically significant $(\mathrm{p}>0.05)$. (Table. I). In our study the Orthodontist preferred the smile esthetics of Extraction cases while Dental professionals and Laypersons preferred Non-extraction.

The Isiksalet al ${ }^{7}$ study, differed in that, Orthodontists gave higher scores to non-extraction, followed by Control and Extraction subjects. Dental Professionals rated the Control group best and Lay persons also rated the control group best showing that they had more similar perceptions as in our study. In both studies Orthodontists gave the lowest scores indicating a more critical appraisal of smile esthetics. The difference between the mean scores given by the three panels for Extraction, Non-extraction and Control groups was not statistically significant, in contrast with our study where the scores given by dental professionals were significantly different.

Lay persons and Dental professionals appeared to have more similar perception of smile esthetics and differed from the orthodontists. The mean actual esthetic scores show that orthodontists in general gave lower 
scores indicating that they had higher esthetic standards and Dental Professionals gave the highest. In Isiksal's ${ }^{7}$ study too, Orthodontists gave lower scores but the lay persons gave the highest scores. These findings agree with those of Isikal $^{7}$ but contrast with that of Hulsey ${ }^{14}$ who reported that lay person had no preference in variables determining smile attractiveness.

The studies of Prahl-Anderson et $\mathrm{al}^{15}$, Brisman $\mathrm{AS}^{16}$, Tedesco et $\mathrm{al}^{17}$, Lundstrom et al ${ }^{18}$ and Kerr et $\mathrm{al}^{19}$ confirm that dentists and laypersons judge esthetics differently. Orthodontists have been sensitized to observe and evaluate features that do not influence the layperson. Kokich ${ }^{20}$ et al demonstrated that general dentists, orthodontists and laypersons detect specific dental discrepancies at varying deviations. Dunn et al's ${ }^{21}$ findings agree with the present study that, lay persons perception of smile esthetics was relevant just as Moore et,al ${ }^{22}$ found that lay persons are able to discriminate between various degree of smile fullness.. Erum et al ${ }^{23}$ found that orthodontists, dentists, laypersons share more similarities than the differences when evaluating dental esthetics. This finding demonstrates the ability of humans to appreciate smile attractiveness even in the absence of technical knowledge. This shows how important it is to consider the patient perception in the treatment planning.

The mean esthetic scores evaluated by three panels for Extraction, Non-extration and Control groups were 3.01, 3.07 and 2.77 respectively. According to this statistical data, all three groups did not differ statistically in the mean esthetic scores evaluated by three panels $(p>0.05)$ (Table. I). This shows that neither the treatment groups nor the control group were seen to have superior smiles and could not be differentiated on the basis of treatment modality. These data corroborate with the findings of Isiksal et al who found no differences in smile esthetic scores between extraction, non -extraction and control groups. These are also in agreement with the findings of Johnston and $\mathrm{Smith}^{5}$ and Gianelley ${ }^{24}$ who found no difference between extraction and non extraction patients. They are in contrast to the findings of Hulsey ${ }^{25}$ where mean rated smile scores of orthodontically treated subjects were significantly poorer than the mean rated smile scores of subjects with normal occlusions. However according to Mackley ${ }^{4}$, to conclude that people with ideal occlusions and accompanying ideal facial proportions who have had no orthodontic treatment is an unjust criticism of orthodontic treatment.

All the panelists gave lower esthetic scores to the control group than the orthodontically treated groups in our study. The reason for this could be that the control group may have exhibited mild individual tooth variation compared to the well aligned treated occlusions of other two groups, leading to lower scores for control group. In contrast Isiksal's ${ }^{7}$ study saw the control group getting the highest scores. As mentioned earlier however there was no statistically significant difference between the esthetic scores of the three groups in both the studies.

Smile esthetics in Extraction cases was almost equally rated by the 3 panel groups. Though, the dental professionals gave generally higher scores, but the difference was not statistically significant ( $\mathrm{p}>0.05)$ (Table.II, Graph.4). This shows more similar agreement on the esthetics of extraction case among the panelists.

The smile esthetics scores in the Non-extraction group showed variations. Dental Professionals gave highest mean scores followed by Laypersons and least by Orthodontists, again indicating a more critical appraisal by orthodontist. The difference between the mean scores of orthodontist and dental professionals was highly significant $(\mathrm{p}<0.001)$ as, was the difference between dental professionals and lay persons. (Table.II, Graph.5). There was distinct disagreement among the raters.

The Control group also received highest esthetic scores from Dental Professionals, followed by Lay persons, and Orthodontist. The difference between the mean esthetic scores given by Dental professional and Orthodontist was statistically significant $(\mathrm{p}<0.05)$. (Table.II.Graph.6), this data points out important differences among the 3 panel groups. Having a better understanding of these similarities and differences will allow practitioners to design treatment plan that take into account the esthetic preferences of both patient and $\operatorname{clinician}^{23}$. 


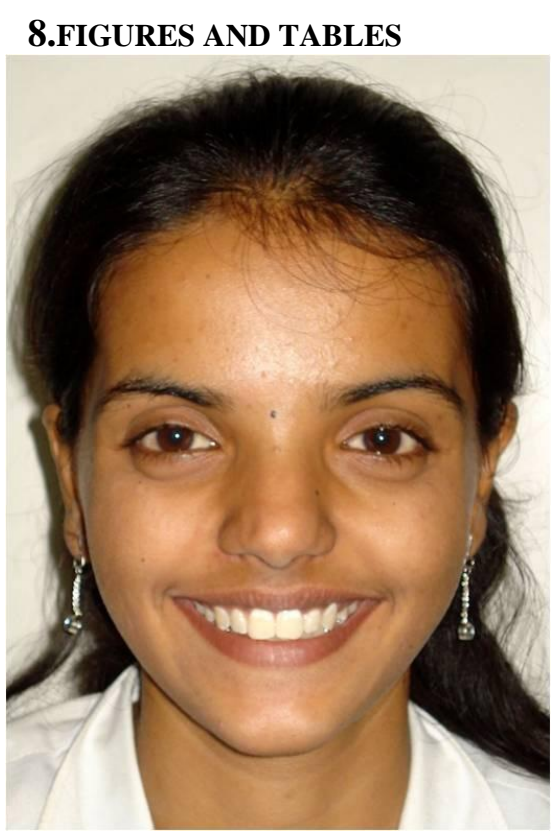

Figure.1. Frontal Smile view.

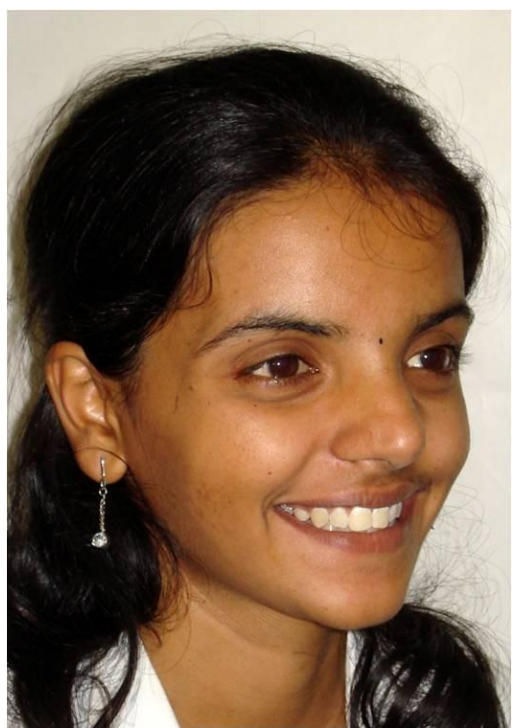

Fig.2. Three-quarter smile view.

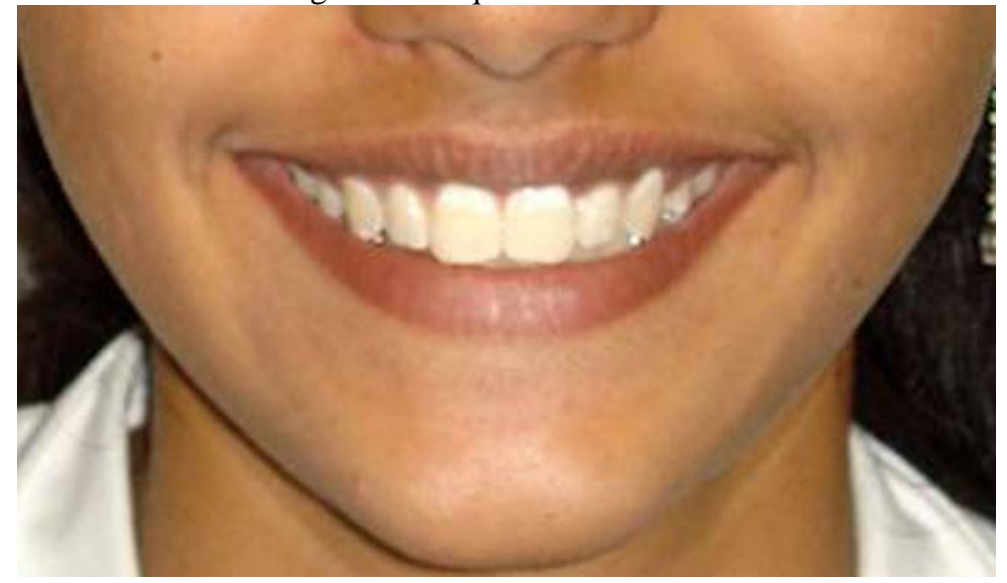

Fig.3. Frontal Smile cropped view. 


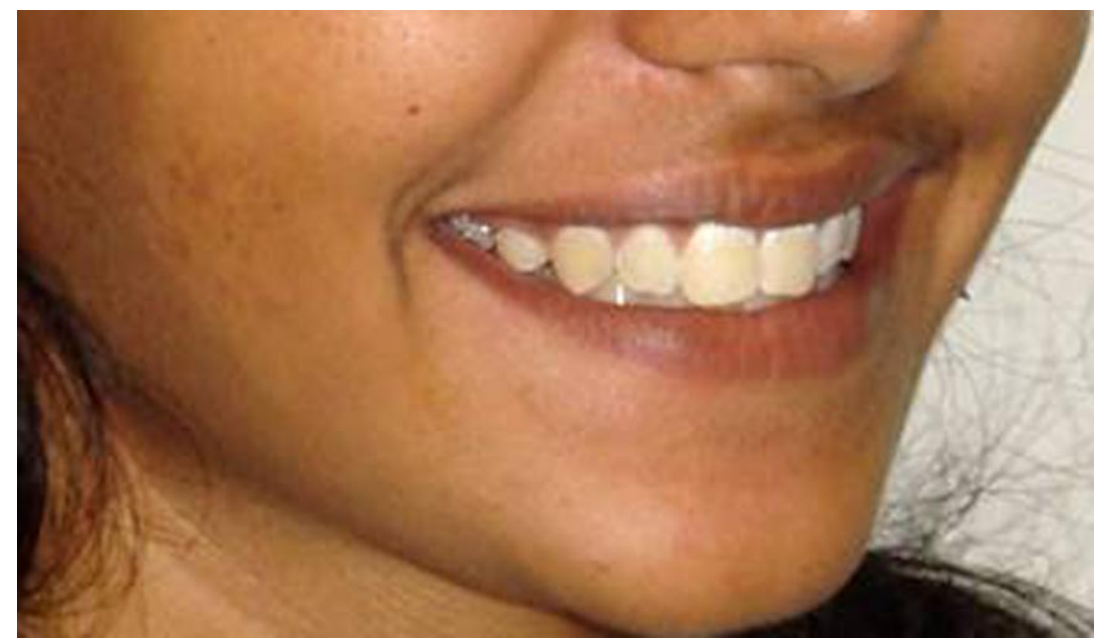

Fig.4. Three quarter smile cropped view.

Table I. Comparison of mean esthetic scores among Extraction, Non-extraction, and Control groups as evaluated by 3 panels

\begin{tabular}{|l|c|c|c|c|c|}
\hline \multicolumn{1}{|c|}{ Panel } & $\begin{array}{c}\text { Extraction. } \\
\mathbf{N = 1 5}\end{array}$ & $\begin{array}{c}\text { Non- } \\
\text { extraction } \\
\mathbf{N = 1 5}\end{array}$ & $\begin{array}{c}\text { Control } \\
\text { group } \\
\mathbf{N = 1 5}\end{array}$ & $\begin{array}{c}\text { ANOVA } \\
\mathbf{F}^{*}\end{array}$ & $\begin{array}{c}\text { P value } \\
\text { Significance }\end{array}$ \\
\hline Orthodontists & $2.96 \pm 0.34$ & $2.81 \pm 0.51$ & $2.6 \pm 0.68$ & 1.7 & $>0.05, \mathrm{NS}$ \\
\hline Dental professionals. & $3.08 \pm 0.36$ & $3.40 \pm 0.36$ & $2.92 \pm 0.53$ & 4.8 & $\begin{array}{c}<0.05, \mathrm{~S} \\
* *\end{array}$ \\
\hline Laypersons & $2.96 \pm 0.28$ & $3.02 \pm 0.41$ & $2.78 \pm 0.53$ & 1.2 & $>0.05, \mathrm{NS}$ \\
\hline $\begin{array}{l}\text { Mean ratings of 3 } \\
\text { panels }\end{array}$ & $3.01 \pm 0.40$ & $3.07 \pm 0.42$ & $2.77 \pm 0.58$ & 2.56 & $>0.05, \mathrm{NS}$ \\
\hline
\end{tabular}

\section{* One-way ANOVA test}

** Note: There is significant difference in non-extraction and control group in the dental professionals

Table. II. Intra group comparison.

\begin{tabular}{|c|c|c|c|c|}
\hline Extraction & Mean & $F^{*}$ Value & P Value, sig & Significant Pairs** \\
\hline Orthodontists. & 2.96 & \multirow{3}{*}{1.2} & \multirow{3}{*}{$>0.05 \mathrm{NS}$} & \multirow{3}{*}{ - } \\
\hline Dental professionals. & 3.08 & & & \\
\hline Lay persons & 2.96 & & & \\
\hline Non-extraction & Mean & F* Value & P Value, sig & Significant Pairs ${ }^{* *}$ \\
\hline Orthodontists & 2.81 & \multirow{3}{*}{16} & \multirow{3}{*}{$<0.001 \mathrm{HS}$} & \multirow{3}{*}{$1 \& 2,2 \& 3$} \\
\hline Dental professionals & 3.40 & & & \\
\hline Lay persons & 3.02 & & & \\
\hline Control & Mean & F* Value & P Value, sig & Significant Pairs ${ }^{* *}$ \\
\hline Orthodontists & 2.60 & \multirow{3}{*}{8.1} & \multirow{3}{*}{$<0.05 \mathrm{~S}$} & \multirow{3}{*}{$1 \& 2$} \\
\hline Dental professinals. & 2.92 & & & \\
\hline Lay persons & 2.78 & & & \\
\hline
\end{tabular}

* Repeated measures ANOVA test

** Bonferroni test. Intra class correlation co efficient $0.82, \mathrm{P}<0.001 \mathrm{HS}$ 


\section{Graph. 1. Mean esthetic scores given by} orthodontists
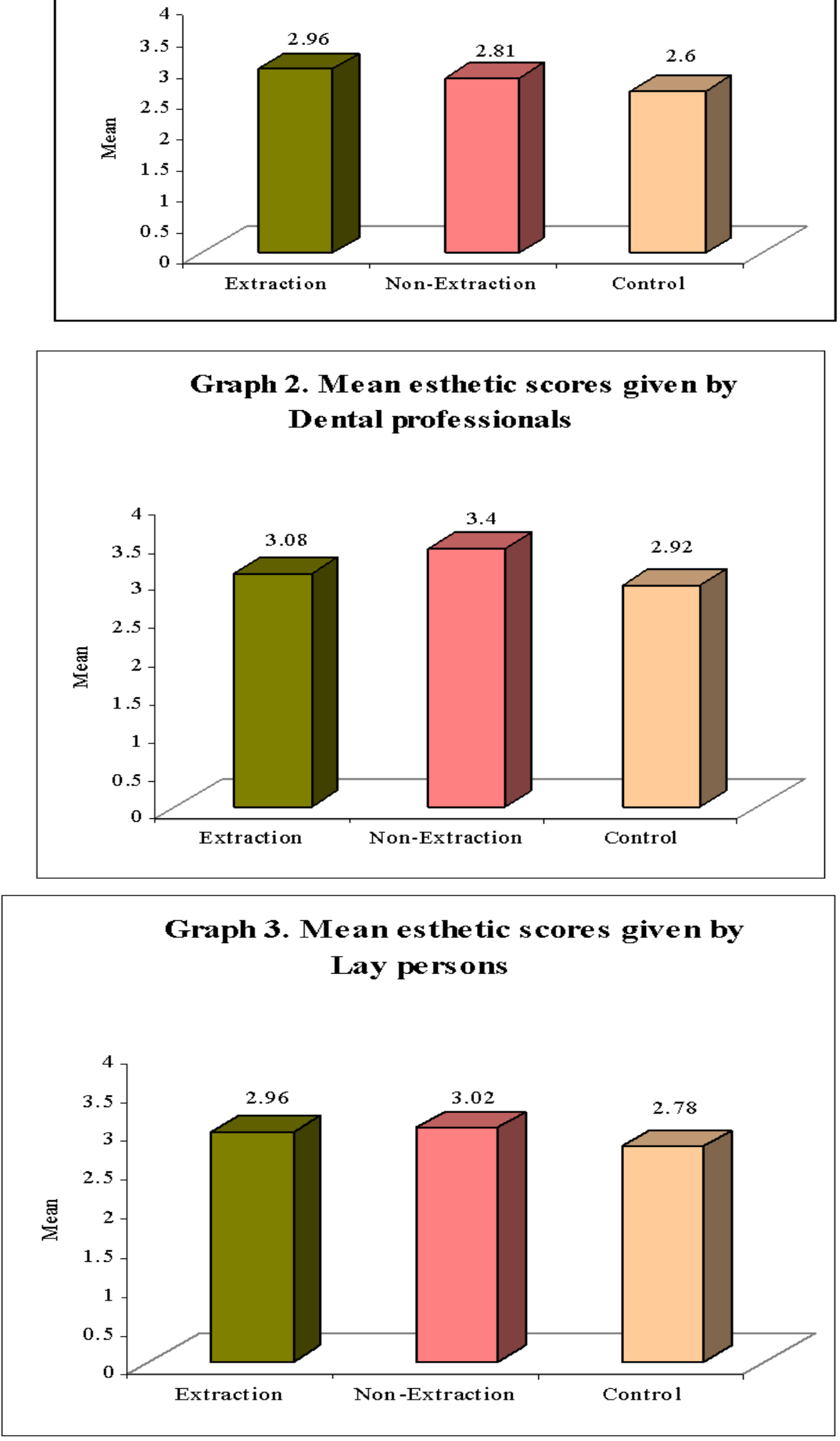

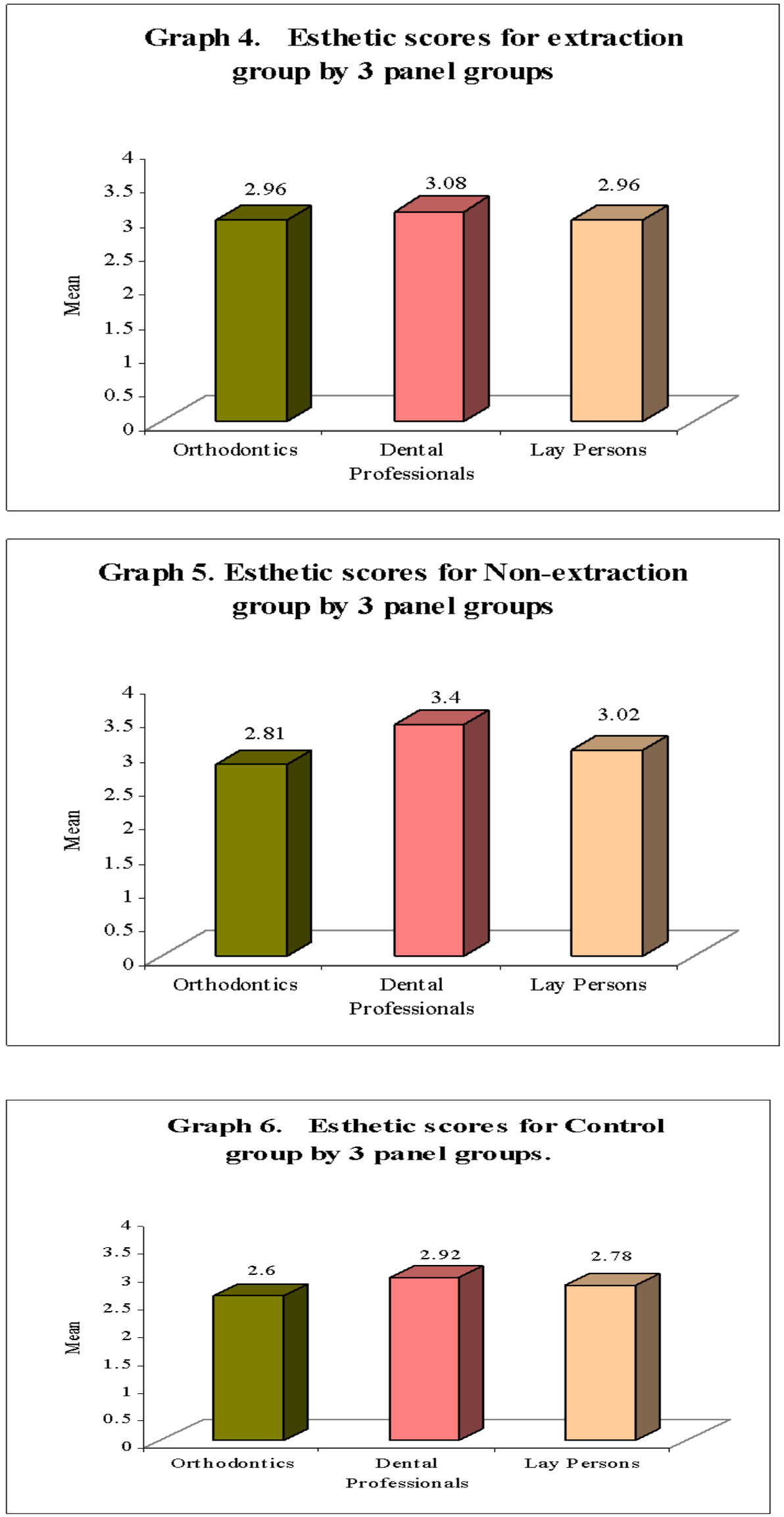


\section{CONCLUSION}

1. Orthodontists, Dental professionals and Layperson share more similarities than differences when evaluating the smile esthetics. Subjects with ideal occlusions and Class I patients treated with or without extractions group were not differentiated in smile esthetics by 3 panels of judges when overall mean esthetic scores were taken.

2. There was significant difference in mean scoring between orthodontist and dental professionals, dental professionals and laypersons in rating smile esthetics in non-extraction group. There was also significant difference among orthodontists and dental professional in rating smile esthetics of control group.

3. Treatment modality alone has no predictable effect on the overall esthetic assessment of a smile. Having better understanding of these similarities and differences allow the practitioners to design treatment plans that take into account the esthetic preferences of the patient and clinician. Even though there were no clear preferences for laypeople as a group, each expressed clear individual preferences. Therefore, treatment must be individualized so that the every patient's unique esthetic preferences can be incorporated.

\section{Acknowledgements}

This project represents the assistance and efforts of many individuals. We would like to acknowledge all the patients who had participated in our study; we also acknowledge the panel groups and the statistician who made us to complete this project successfully.

\section{REFERENCES}

[1] Turkkahraman H, Gokalp H, Facial profile preferences among various layers of Turkish population. Angle Orthod2004; 74: 640647.

[2] Snow SR. Esthetic Smile Analysis of Maxillary Anterior Tooth Width: The Golden Percentage. J Esthet Dent 1999 11:177-84.

[3] Farhad B Naini, James P Moss and Daljit S Gill. The enigma of facial beauty: Esthetics, proportions, deformity and controversy. Am J OrthodDentofacialOrthop 2006; 130: 277-82

[4] Mackley RJ. An evaluation of smiles before and after orthodontic treatment. Angle Orthod 1993; 63(3):183-90.

[5] Johnson DK and Smith JS. Smile esthetics after orthodontic treatment with and without extraction of four first premolars. Am J OrthodDentofacOrthop 1995; 108: 162-7.

[6] Zachrisson BU. Esthetic Factors Involved in Anterior Tooth Display and the Smile: Vertical Dimension. J ClinOrthod 1998; 35(7): $432-45$.

[7] Isıksal E, Hazar S, and Akyalçınc.S Smile esthetics: Perception and comparison of treated and untreated smiles Am J OrthodDentofacialOrthop 2006; 129:8-16.

[8] Mir CF, Silva E, Barriga MI, Lagravere MO, Major PW. Lay person's perception of smile aesthetics in dental and facial views, J Orthod 2004; 31: 204-09.

[9] Wylie WL. The Mandibular incisor-Its Role in Facial Esthetics; Angle Orthod 1955; 25: 32-41.

[10] Peck S, Peck L, Kataja M. The gingival smile line. Angle Orthod 1992; 62(2): 91-100.

[11] Tjan AH,Miller GD, Some esthetic factors in a smile. J Prosthet Dent 1984; 51: 24-28.

[12] Vig RG,Brundo GC.Kinetics of anterior tooth display.J Prosthet Dent 1978;39:502-504.

[13] Frush JP and Fisher RD. How Dentogenic Interprets the Personality factor. J Prosthet Dent 1956, 6: 441-449.

[14] Rigsbee OH, Sperry TP, BeGole EA. The influence of facial animation on smile characteristics. Int J Adult OrthodOrthogSurg 1988; 3: 233-39.

[15] Prahl-Andersen B, Boersma H, van der Linden FPGM, Moore AW. Perceptions of dentofacial morphology by laypersons, general dentists, and orthodontists. J Am Dent Assoc 1979; 98: 209-12.

[16] Brisman AS. Esthetics: A comparison of dentists and patients concepts. J Am Dent Assoc 1980; 100: $345-52$.

[17] Tedesco LA, Albino JE, Cunat JJ, Green LJ, Lewis EA, Slakter MJ. A dental-facial attractiveness scale. Part 1. Reliability and validity. Am J OrthodDentofacialOrthop 1983; 83: 38-46.

[18] Lundstrom A, Woodside DG, Popovich F. Panel assessments of facial profile related to mandibular growth direction. Eur J Orthod 1987; 9: 271-8

[19] Kerr WJS, O'Donnell JM. Panel perception of facial attractiveness. Br J Orthod 1990; 17: 299-304.

[20] Kokich VO Jr, Kiyak HA, SharpioPA.Comparing the perception of dentists and lay people to altered dental esthetics. J Esthet Dent 1999; 11: 311- 324

[21] Dunn.WJ, Murchison DF, Broom JC. Esthetics: a comparison of dentists and parents concepts. J Am Dent Assoc 1980; $100: 345-52$.

[22] Moore T, Southard KA, Casko JS, Qian F and Southard TE. Buccal corridors and smile esthetics. Am J Orthod Dentofacial Orthop 2005; 127: 208-13.

[23] Erum GE, Fida M. Changes in smile parameters as perceived by orthodontists, dentists, artists, and laypeople; World J Orthod 2008; 9: $132-140$

[24] Kim.E, Gianelly .A., Extraction vsNonextraction: Arch widths and Smile Esthetics.Angle Orthod $2003 ; 73$ :354-358.

[25] Hulsey CM. An esthetic evaluation of lip-teeth relationships present in the smile. Am J OrthodDentofacialOrthop1970; 57 : $132-44$. 